\title{
Body mass index and serum lipid profile influence serum prostate-specific antigen in Chinese men younger than 50 years of age
}

\author{
Ming Liu ${ }^{1}$, Jian-Ye Wang ${ }^{1}$, Ling Zhu ${ }^{2}$ and Gang Wan ${ }^{3}$
}

This study is to assess the potential factors that could affect the serum prostate-specific antigen (PSA) level in healthy younger men. We evaluated the associations of age, body mass index (BMI) and serum lipid profile with serum PSA level in 6774 Chinese men (aged 20-49 years) who received a routine health examination. Eligible men were classified into 10-year age groups. BMI was categorized as underweight $(<18.5)$, normal (18.5-22.9), overweight (23.0-24.9), obese (25.0-29.9) and very obese $(>30)$ according to the redefined World Health Organization (WHO) criteria for the Asia-Pacific region. PSA levels were compared among groups as well. In multiple linear regression analysis, PSA was positively correlated with age $(P<0.0001)$. Negative correlations existed between PSA and BMI $(P<0.0001)$ and triglyceride level $(P=0.01)$. No relationship could be found between PSA and serum cholesterol $(P=0.711)$ or high-density lipoprotein (HDL; $P=0.665)$. In addition, we found that serum PSA levels increased with age and decreased with BMI. Our study demonstrates that age, BMI and triglyceride levels influence the PSA level in men $<50$ years of age. Asian Journal of Andrology (2011) 13, 640-643; doi:10.1038/aja.2010.104; published online 20 December 2010

Keywords: age; body mass index; prostate-specific antigen; serum lipid profile

\section{INTRODUCTION}

Serum prostate-specific antigen (PSA) concentration is one of the most useful tumour markers available. Since its introduction into clinical practice, it has led to remarkable changes in the diagnosis, staging and treatment of prostate cancer. Although PSA has high tissue specificity, it may be affected by many factors unrelated to prostate diseases. However, most of the studies related to PSA have been carried out in populations of men over 50 years of age, and the high incidence of benign prostatic hyperplasia, prostate cancer and use of $5 \alpha$-reductase inhibitors in this population may influence the analysis. ${ }^{1,2}$ To elucidate the factors influencing PSA in young men, our study was performed in a routine health examination population. The influence of body mass index (BMI), age and triglyceride, cholesterol and high-density lipoprotein (HDL) levels on PSA level was analysed retrospectively.

\section{MATERIALS AND METHODS}

\section{Population selection and analysis}

A total of 7117 men, aged 20-49 years and residing in downtown Beijing, visited the Beijing Hospital (Beijing, China), for routine health examinations between 9 September 2006 and 15 November 2008. Although in China, PSA testing is usually suggested only for men aged over 50 years, the serum PSA was measured in these younger men because they had chosen a fixed set of examinations that included PSA assessment. All the men had blood drawn before prostatic manipulation, including a digital rectal examination. Of the 7117 men examined, 343 were excluded: 47 because they had a PSA concentration $>4 \mathrm{ng} \mathrm{ml}^{-1}, 35$ because of prostatic nodules and 261 because of lack of PSA results. Age, BMI, PSA, cholesterol, triglyceride and HDL were recorded in the other 6774 men. The research protocol was approved by the Medical Ethics Committee of Beijing Hospital. PSA was measured by electrochemiluminescence immunoassay on an ARCHITECT i4000 (Abbott, Abbott Park, IL, USA). BMI was calculated as weight divided by height squared $\left(\mathrm{kg} \mathrm{m}^{-2}\right)$. Eligible men were classified into 10-year age groups. BMI was categorized as underweight (BMI: <18.5), normal (BMI: 18.5-22.9), overweight (BMI: 23.0-24.9), obese (BMI: 25.0-29.9) and very obese (BMI: $>30$ ) according to the redefined World Health Organization (WHO) criteria for the Asia-Pacific region. ${ }^{3}$

\section{Statistics}

An analysis of variance and the Student-Newman-Keuls test were used to compare the differences in PSA levels among the age and BMI groups. Because PSA does not exhibit a normal distribution, it was analysed as continuous terms after logarithmic transformation. Multiple linear regression analysis was used to evaluate the interrelationship between PSA and other factors. All statistical analyses were carried out using SPSS 12.0 software (SPSS Inc., Chicago, IL, USA), and $P$ values $<0.05$ were considered statistically significant. 
Table 1 Distribution of the parameters

\begin{tabular}{|c|c|c|c|c|c|c|}
\hline & Mean (s.d.) & P5 & P25 & P50 & P75 & P95 \\
\hline PSA (ng ml $\left.{ }^{-1}\right)$ & $0.90(0.56)$ & 0.31 & 0.52 & 0.76 & 1.11 & \\
\hline $\mathrm{BMI}$ & $25.5(3.2)$ & 20.3 & 23.4 & 25.4 & 27.5 & 31.0 \\
\hline Triglycerides (mmol $\mathrm{I}^{-1}$ ) & $1.94(1.67)$ & 0.64 & 1.04 & 1.52 & 2.26 & 4.50 \\
\hline Cholesterol $\left(\mathrm{mmol} \mathrm{I}^{-1}\right)$ & $5.02(0.96)$ & 3.65 & 4.37 & 4.93 & 5.56 & 6.6 \\
\hline $\mathrm{HDL}\left(\mathrm{mmol} \mathrm{I}^{-1}\right)$ & $1.22(0.26)$ & 0.87 & 1.04 & 1.18 & 1.37 & 1.6 \\
\hline
\end{tabular}

Abbreviations: BMI, body mass index; HDL, high-density lipoprotein; PSA, prostatespecific antigen.

\section{RESULTS}

The mean ( \pm s.d.) age of the study population was 39.2 ( \pm 6.9 ) years; the other parameters are shown in Table 1. Figure 1 is a scatter plot of PSA distribution.

In a multiple linear regression analysis, PSA was positively correlated with age $(P<0.0001)$. Negative correlations existed between PSA and BMI $(P<0.0001)$ and triglyceride $(P=0.01)$. No relationship could be found between PSA and serum cholesterol $(P=0.711)$ or HDL $(P=0.665)$.

When the subjects were classified into age groups, there was an increasing trend in serum PSA level with increasing age. After logarithmic transformation, PSA level was different among the 10-year age groups $(P<0.001$; Table 2$)$.

When the subjects were divided into BMI groups according to the redefined WHO criteria for the Asia-Pacific region, serum PSA levels
Table 2 Serum PSA level by age group ( $\mathrm{n} \mathrm{ml}^{-1}$ )

\begin{tabular}{|c|c|c|c|c|c|c|c|}
\hline $\begin{array}{l}\text { Age group } \\
\text { (years) }\end{array}$ & $\begin{array}{l}\text { Number (\%) } \\
\text { of patients }\end{array}$ & 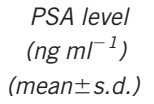 & P5 & $P 25$ & $P 50$ & $P 75$ & P95 \\
\hline 20-29 & $906(13.4)$ & $0.84 \pm 0.54 *$ & 0.30 & 0.50 & 0.70 & 1.02 & 1.79 \\
\hline 30-39 & 2379 (35.1) & $0.87 \pm 0.52 *$ & 0.31 & 0.51 & 0.75 & 1.07 & 1.85 \\
\hline $40-49$ & 3489 (51.5) & $0.93 \pm 0.59 *$ & 0.32 & 0.54 & 0.78 & 1.15 & 2.09 \\
\hline
\end{tabular}

Abbreviation: PSA, prostate-specific antigen.

$* P<0.001$, compared between each two age groups.

were different among BMI groups in all ages. Analysis by StudentNewman-Keuls test showed that the PSA level of the BMI $\geqslant 30$ group was significantly different from those of the other BMI groups $(P<0.01)$. However, no difference was found between other BMI groups $(P>0.05$, Figure 2$)$.

\section{DISCUSSION}

Although PSA has high tissue specificity, it can be affected by several factors besides prostatic disease. Age is one of the most significant of these factors. There are two phases of a man's life in which dramatic changes in PSA level occur: puberty and old age. The PSA level is generally undetectable at the beginning of puberty and increases rapidly during pubertal development. ${ }^{4}$ Many studies in elderly men have shown that PSA is positively correlated with age in this population. ${ }^{5-7}$ However, the potential high incidence of benign prostatic

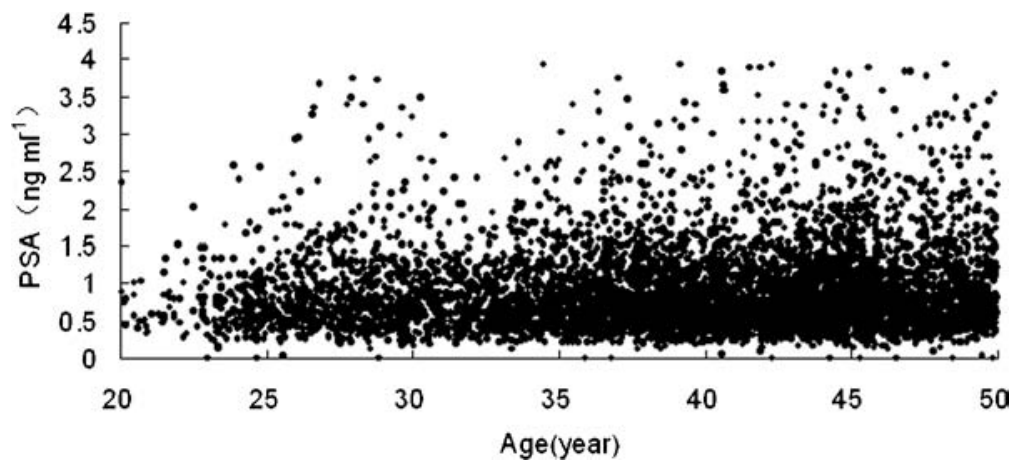

Figure 1 Scatter plot of PSA distribution by age. PSA, prostate-specific antigen.

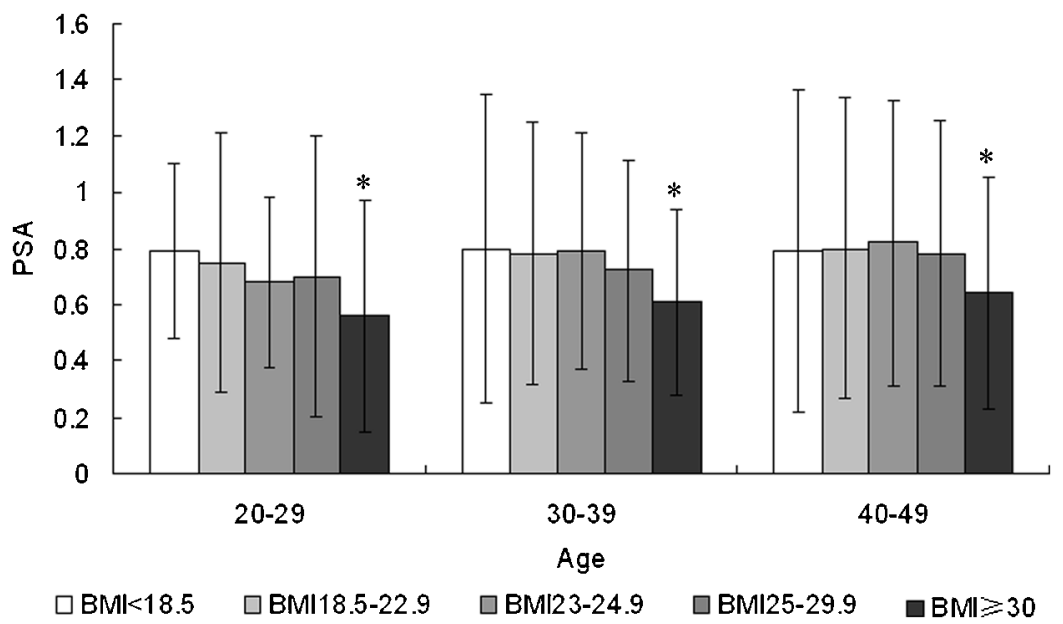

Figure 2 The relationship between median serum PSA level and BMI in different age groups. *PSA level of the BMI $\geqslant 30$ group was significantly different from those of the other BMI groups $(P<0.01)$. No difference was found between other BMI groups $(P>0.05)$. BMI, body mass index; PSA, prostate-specific antigen. 
hyperplasia and prostate cancer in aged people may bias this correlation. Our study aimed to investigate factors correlated with PSA in the adult male population aged between 20 and 49 years to avoid the influences of both puberty and some potential prostatic diseases. A positive correlation was found between age and PSA in our multiple linear regression analysis. The mean PSA level increased from $0.84 \mathrm{ng} \mathrm{ml}^{-1}$ in the $20-29$ years age group to $0.93 \mathrm{ng} \mathrm{ml}^{-1}$ in the 40-49 years age group. Because the lower age limit of PSA screening is usually 40 years, data on PSA level in young adults are limited. Several studies have also demonstrated that age and PSA are positively correlated in Western young males, but the mean PSA levels in these studies differed from ours. Baillargeon et al. ${ }^{8}$ performed a study in Western men and found mean PSA levels of $0.65 \mathrm{ng} \mathrm{ml}^{-1}$ in the 20-39 years age group and $0.81 \mathrm{ng} \mathrm{ml}^{-1}$ in the $40-49$ years age group, which are lower than our respective values. However, $81.4 \%$ of the men in that study were classified as either overweight or obese, conditions that may lower PSA level. Another study, performed by Preston et al. ${ }^{9}$ reported even lower PSA values. They found mean PSA levels in white men of 0.47 in the 20- to 29-year group, 0.55 in the 30- to 39-year group and 0.49 in the 40- to 49-year group; the levels in AfricanAmericans were 0.51 in the 20 - to 29 -year group, 0.57 in the 30 - to 39 -year group and 0.60 in the 40 - to 49 -year group. The study had the limitation that the specimen analysed was frozen serum-the mean storage time was 4.18 years, which may have affected the serum PSA levels. Therefore, we cannot draw any conclusions about differences in PSA between Chinese and Western people.

In this study, we retrospectively analysed results from routine health examinations in Beijing Hospital. The participants in the health checkup were local residents of Beijing. Because no records of prostate cancer history, prostate volume or use of $5 \alpha$-reductase inhibitors could be obtained, we chose a population aged 20-49 years, so as to avoid the interference of these elements on PSA. Patients with a PSA level $>4 \mathrm{ng} \mathrm{ml}^{-1}$ were excluded from the study because they did not agree to undergo a biopsy to rule out the prostate cancer. These are potential limitations of our study, given that we could not expand the analysis to men aged over 50 years, which is the age group with high prostate cancer prevalence. Another limitation is that even in these low-PSA men, there is the possibility of undiagnosed prostate cancer.

There have been previous studies on the relationship between BMI and PSA. Although some of these demonstrated no correlation between BMI and PSA, the results of most of them support the finding that, compared with non-obese men, obese men have significantly lower PSA levels. ${ }^{10}$ The discrepancy between these results may be traced to the different age ranges of the populations, ways of evaluating patients with abnormal PSA and statistical methods performed in the studies. Race is another factor that apparently influences PSA levels. Some large-scale investigations based on Asian populations have also sustained the inverse correlation between PSA and BMI in younger men. In Korean men $<60$ years of age, Han et al. ${ }^{11}$ found that PSA was significantly interrelated with BMI, age and HDL. Kim et al. ${ }^{12}$ found an inverse correlation in men 40-59 years old, but not in those 60-79 years old. In our study, BMI correlated inversely with serum PSA levels in the multiple linear regression analysis, although the correlation was weak. When we compared PSA levels among BMI groups using the Student-Newman-Keuls test, we found that only the BMI $\geqslant 30$ group differed from the others. The men with BMI $\geqslant 30$ had $0.18 \mathrm{ng} \mathrm{ml}^{-1}(19.3 \%)$ less serum PSA than those with BMI 18.5-22.9 $\left(0.75 \pm 0.48 \mathrm{ng} \mathrm{ml}^{-1}\right.$ versus $\left.0.93 \pm 0.59 \mathrm{ng} \mathrm{ml}^{-1}\right)$. The intergroup PSA comparisons did not show any differences in men with BMI $<30$. A study in Japanese men performed by Ando et al. ${ }^{13}$ showed similar results: PSA decreased significantly with BMI. Although they did not report the significance of intergroup PSA level differences, only the BMI $>30$ group (mean PSA: $0.67 \mathrm{ng} \mathrm{ml}^{-1}$ ) appeared to be different from the others (mean PSA: $0.81-0.84 \mathrm{ng} \mathrm{m}^{-1}$ ). Most of the Asian studies used the BMI classification system according to the redefined WHO criteria for the Asia-Pacific region. However, the main difference between this system and the international one is the reclassification in $\mathrm{BMI}<25$, and this discrepancy would not affect the conclusions of these studies because most apparent disparities in PSA levels were in the BMI $>30$ group.

Several explanations of the relationship between BMI and PSA have been postulated. One could be the alteration of serum androgen level because obese men usually have a lower androgen level. The growth or differentiation of normal prostate is affected by androgens, ${ }^{14}$ and androgens may affect PSA production as a result of the androgen response element in the PSA promoter region. ${ }^{15}$ Another postulation is that men with higher BMI have higher circulating plasma volumes, which lower the PSA concentrations through haemodilution. This postulation was recently supported by two large retrospective studies, ${ }^{16,17}$ one of which examined prostate cancer patients and the other individuals without cancer. The investigators estimated PSA mass as PSA concentration times estimated plasma volume and showed that although PSA showed an inverse trend with BMI, PSA mass did not. Thus, they demonstrated that haemodilution accounted for this inverse correlation between PSA and BMI.

In our study, we found a negative correlation between PSA and triglyceride, but no correlation between PSA and cholesterol or HDL. There have been few studies on the relationship between PSA and serum lipid profile. One case-control study showed that cholesterol level was associated with the risk of high-grade prostate cancer, but the authors found neither association between cholesterol and the incidence of prostate cancer nor did they examine the influence of cholesterol on PSA. ${ }^{18}$ Further studies are needed to obtain a full understanding of the mechanism that underlies the correlation between serum lipid profile and PSA.

Our study demonstrates that age, BMI and triglyceride level affect PSA level in males aged 20-49 years. However, the magnitude of this influence is minor. Whether clinical practice would be affected is not yet clear.

\section{AUTHOR CONTRIBUTIONS}

ML designed and performed experiments, analysed data and wrote the paper. JYW designed, support and supervised the project. LZ supervised the study. GW analysed the data and performed the statistical study.

\section{COMPETING FINANCIAL INTERESTS}

The authors declare no financial conflict interests.

\section{ACKNOWLEDGMENT}

This work was supported by a grant from Capital Key Clinical Technology Research, China (Z090507017709003)

1 Kobayashi M, Nukui A, Morita T. Serum PSA and percent free PSA value changes after antibiotic treatment. A diagnostic method in prostate cancer suspects with asymptomatic prostatitis. Urol Int 2008; 80: 186-8.

2 Thompson IM, Chi C, Ankerst DP, Goodman PJ, Tangen CM et al. Effect of finasteride on the sensitivity of PSA for detecting prostate cancer. J Natl Cancer Inst 2006; 98 : 1128-31.

3 WHO expert consultation. Appropriate body-mass index for Asian populations and its implications for policy and intervention strategies. Lancet 2004; 363: 157-63. 
4 Vieira JG, Nishida SK, Pereira AB, Arraes RF, Verreschi IT. Serum levels of prostatespecific antigen in normal boys throughout puberty. J Clin Endocrinol Metab 1994, 78: 1185-7

5 Loeb S, Roehl KA, Catalona WJ, Nadler RB. Is the utility of prostate-specific antigen velocity for prostate cancer detection affected by age? BJU Int 2008; 101: 817-9.

6 Young DC, Dae RK, Chung MN, Young SK, Soung YC et al. Age-specific prostatespecific antigen reference ranges in Korean men. Urology 2007; 70: 1113-6.

7 Felix KC, Georg CH, Paul P, Andrea G, Luc V et al. Distribution of prostate specific antigen (PSA) and percentage free PSA in a contemporary screening cohort with no evidence of prostate cancer. BJU Int 2007; 100: 37-41.

8 Baillargeon J, Pollock BH, Kristal AR, Bradshaw P, Hernandez J et al. The Association of body mass index and prostate-specific antigen in a population-based study. Cancer 2005; 103: 1092-5.

9 Preston DM, Levin LI, Jacobson DJ, Jacobsen SJ, Rubertone M et al. Prostate-specific antigen levels in young white and black men 20 to 45 years old. Urology 2000; 56: 812-6.

10 Fowke JH, Motley SS, Cookson MS, Concepcion R, Chang SS et al. The association between body size, prostate volume and prostate-specific antigen. Prostate Cance Prostatic Dis 2007; 10: 137-42.

$11 \mathrm{Han} \mathrm{JH}$, Chang IH, Ahn SH, Kwon OJ, Bang SH et al. Association between serum prostate-specific antigen level, liver function tests and lipid profile in healthy men. BJU Int 2008; 102: 1097-101.
12 Kim YJ, Han BK, Hong SK, Byun SS, Kim WJ et al. Body mass index influences prostate-specific antigen in men younger than 60 years of age. Int J Urol 2007; 14 1009-12.

13 Ando R, Nagaya T, Hashimoto Y, Suzuki S, Itoh Y et al. Inverse relationship between obesity and serum prostate-specific antigen level in healthy Japanese men: a hospitalbased cross-sectional survey, 2004-2006. Urology 2008; 72: 561-5.

14 Platz EA, Giovannucci E. The epidemiology of sex steroid hormones and their signaling and metabolic pathways in the etiology of prostate cancer. J Steroid Biochem Mol Biol 2004; 92: 237-53.

15 Riegman PH, Vlietstra RJ, Vander KJ, Brinkmann AO, Trapman J. The promoter of prostate-specific antigen gene contains a functional androgen responsive element. Mol Endocrinol 1991; 5: 1921-30.

16 Banez LL, Hamilton RJ, Partin AW, Vollmer RT, Sun L et al. Obesity-related plasma hemodilution and PSA concentration among men with prostate cancer. JAMA 2007; 298: 2275-80.

17 Grubb RL, Black A, Izmirlian G, Hickey TP, Pinsky PF et al. Serum Prostate-specific antigen hemodilution among obese men undergoing screening in the prostate, lung, colorectal, and ovarian cancer screening trial. Cancer Epidemiol Biomarkers Prev 2009; 18: 748-51.

18 Platz1 EA, Clinton SK, Giovannucci E. Association between plasma cholesterol and prostate cancer in the PSA era. Int J Cancer 2008; 123: 1693-8. 